\title{
La apertura del Centre Pompidou y del Museo Estatal Ruso de San Petersburgo en Málaga (2015)*
}

\section{La colección (muestra permanente) y Corps simples. A ver cómo te mueves (primera temporal), en el Centre Pompidou Málaga}

Nosotros somos el objeto de la primera exposición permanente del Centre Pompidou Málaga. Esto es, el sujeto contemporáneo. La identidad, cada vez más fluctuante e imprecisa, el cambio de paradigma en la representación humana, que quedó -nunca mejor dicho- dinamitada en el siglo XX, así como la constitución del cuerpo como arma y como medio artístico cargado de implicaciones críticas, reivindicativas y políticas, son los principales cimientos del conjunto expositivo con el que queda inaugurado el Centre Pompidou Málaga y que ha sido comisariado por Brigitte Leal. Obras que no solo responden a su calidad o a la autoría -muchos de los artistas son fundamentales, desde las vanguardias a la actualidad-, sino a su idoneidad para armar un discurso que nos ofrezca un retrato polimorfo del ser humano de los siglos XX y XXI a través de su representación, de ahí que algunas presencias no gocen de la misma fortuna crítica. En definitiva, el conjunto expositivo se convierte en un revelador espejo que origina preguntas y respuestas sobre nosotros mismos.

La presentación del Centre Pompidou Málaga, en septiembre de 2014, permitió conocer algunas líneas fundamentales del proyecto. La principal estribaba en su constitución como una suerte de «laboratorio», un lugar donde ensayar nuevos modelos museográficos, nuevos conceptos de museo y nuevas relaciones con el entorno -el tiempo dirá si se cumple esa anhelada condición experimental, aunque hasta la fecha, algunos servicios como el de «mediación cultural» han demostrado esa vis innovadora, configurándose como un verdadero acierto y reclamo-. Tal vez, el primer ensayo consista en los fondos seleccionados, que evitan elaborar un discurso historiográfico a favor de una muestra temática que recorre transversalmente la creación artística del último siglo mediante asuntos medulares que ciertamente nos comprometen. El centenar de piezas se articula en cinco bloques: «Metamorfosis», «Autorretratos», «El hombre sin rostro», «El cuerpo político» y «El cuerpo en pedazos».

La selección hace gala de cierta sofisticación y elegancia que sortea aspectos crudos, aunque los hay, cómo no. No en vano, una categoría como «lo abyecto» se escenifica en la representación humana. En la sugerente multiplicación de diálogos entre obras y artistas de momentos muy lejanos se aborda con brillantez la condición cada vez más mutable de la identidad -cuán reales son ya algunas identidades híbridas-, cómo lo grotesco, surgido de la vulneración de la representación humana, se ha convertido en una categoría privilegiada de nuestro tiempo, o cómo el rostro ha sido testigo y efecto del drama y el oprobio -piensen en la obra de Jean Fautrier-. De hecho, el siglo XX ha visto cómo lo grotesco se ha convertido en la categoría por excelencia, en una categoría que vendría a ser la fiel representación de ese periodo. Tiempo que nos ha mostrado cómo la imagen humana se ha vulnerado deviniendo, muchas veces, espantajo o burda parodia de sí misma. El XX, con tanto oprobio, nos ha devuelto reveladoramente una imagen bifronte y consecuente de nosotros: la maldad y la «infrahumanidad». Los Rehenes del mencionado Fautrier o los "homúnculos» de Millares son una imagen de un ser humano que es menos humano, que no llega a esa condición, que la ve rebajada o ultrajada por los acontecimientos que él mismo ha desencadenado -ya saben, «el hombre es el lobo para el hombre»-, que sentenciara Plauto.

El recorrido, en algún momento, resulta apabullante. Sería imposible trasladar a estas páginas los numerosos diálogos que se establecen. A excepción de la instalación ambiental de Christian Boltanski, de una ausencia que sobrecoge y «pellizca», y de la sección dedicada al «Cuerpo

* Versiones ampliadas de «Nosotros», crítica publicada en el diario Sur el 29 de marzo de 2015, primer día de apertura del Centre Pompidou Málaga, y de las críticas «Relatarnos su historia» y "La posibilidad de un puente», publicadas respectivamente en el diario Sur (26 de marzo de 2015, día siguiente de la inauguración) y en Abc Cultural (3 de abril de 2015). 


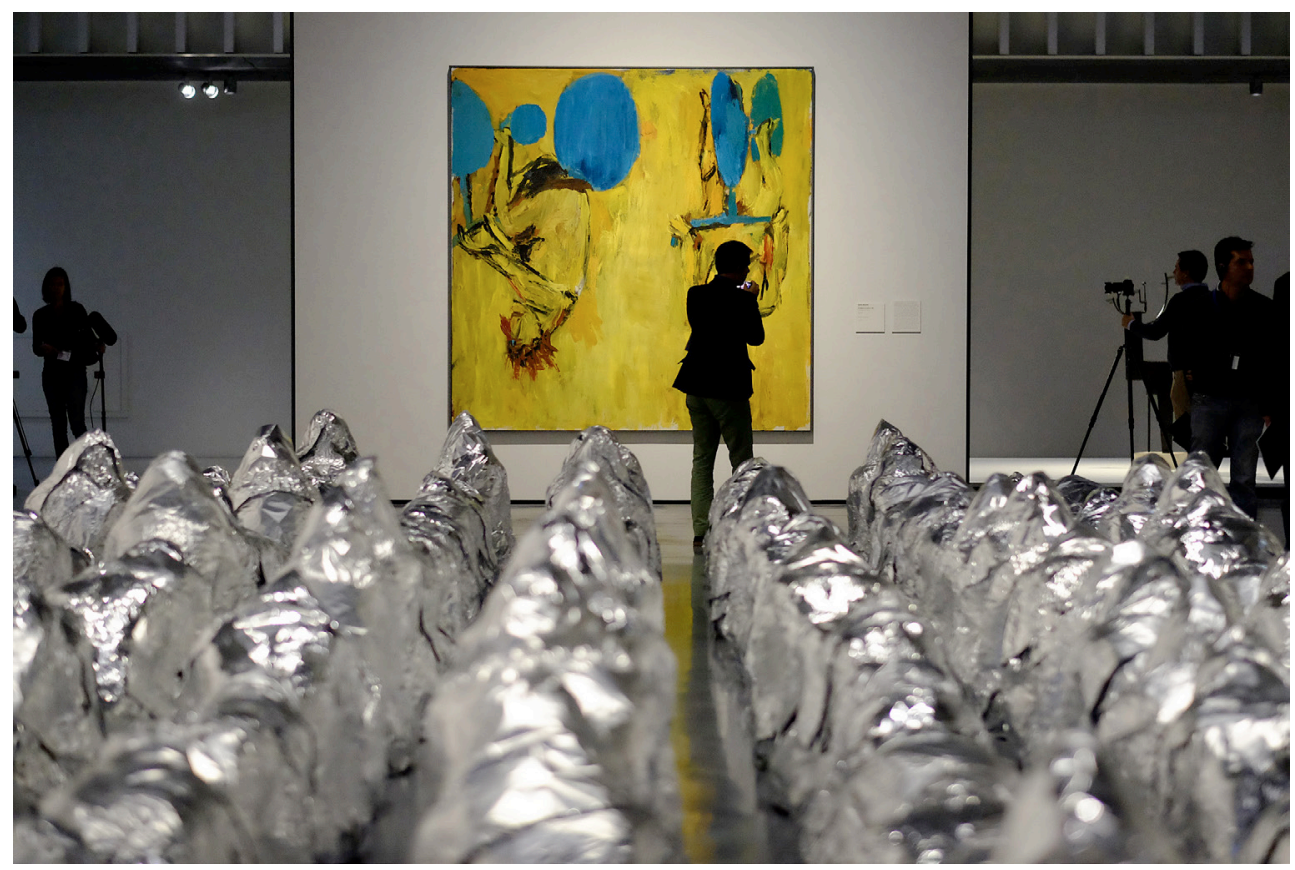

Vista del Centre Pompidou

político", las obras no se exponen de modo que acentúen su autorreferencialidad, sino que se presentan centrífugas, proyectándose continuamente y entrando en diálogos de muy distinta índole. Solo citaremos varios casos: el «duelo» entre una desasosegante instalación de George Segal y la escultura mecánica de Jean Tinguely; se enfrentan, pues, la angustiosa soledad del sujeto contemporáneo -con Edward Hopper en la memoria- y la condición espiritual y animista de una suerte de «doble chamánico» del artista; se enfrentan, también, el pop, aunque el más ácido, y el nuevo realismo, la respuesta francesa al primero. Otra confrontación es la que se produce en la enorme nave central con la crítica instalación escultórica de Kader Attia de por medio, compuesta por decenas de siluetas envueltas en figuradas mantas térmicas, la aniquilación de la persona empujada a convertirse en inmigrante y fantasma. El diálogo que cabe destacar es el que se produce entre el surrealismo desplegado en una de las enormes paredes y los neo-expresionismos en la otra, con Picasso como pattern, tal como figuró para la pintura posmoderna en A New Spirit in Painting, la trascendental exposición desarrollada en la Royal Academy de Londres en 1981; a saber, el cuerpo despedazado como leitmotiv, cosificado in- cluso, pero una lectura historiográfica emerge para señalar la filiación del neo-expresionismo respecto al surrealismo.

Esa elegancia y sofisticación hacen que la experiencia no esté volcada a la "sacudida", al shock, que puede desencadenar un asunto como la representación del cuerpo, especialmente en alguna sección como «El cuerpo en pedazos», en la que podrían tener presencia Jacques André Boiffard con sus fragmentos corporales sobredimensionados y Hans Bellmer con sus poupées. De hecho, se echa en falta más fotografía, una "damnificada» de este relato, pero no por la ausencia de la disciplina -alguna hay-, sino por su capacidad para documentar transformaciones en el cuerpo. Sin ir más lejos, la fragmentación corporal y las enucleaciones que nacen en el surrealismo se presentan aquí a través de la pintura -la pared es simplemente extraordinaria- en lugar de la mucho más punzante fotografía surrealista. Esta ausencia ha de obedecer a algo tan prosaico pero fundamental como el tamaño, ya que se opta por grandes pinturas para acomodarse a las monumentales dimensiones de la pared y de la propia nave central del equipamiento, por lo que no encontraremos un montaje propiamente escenográfico. 


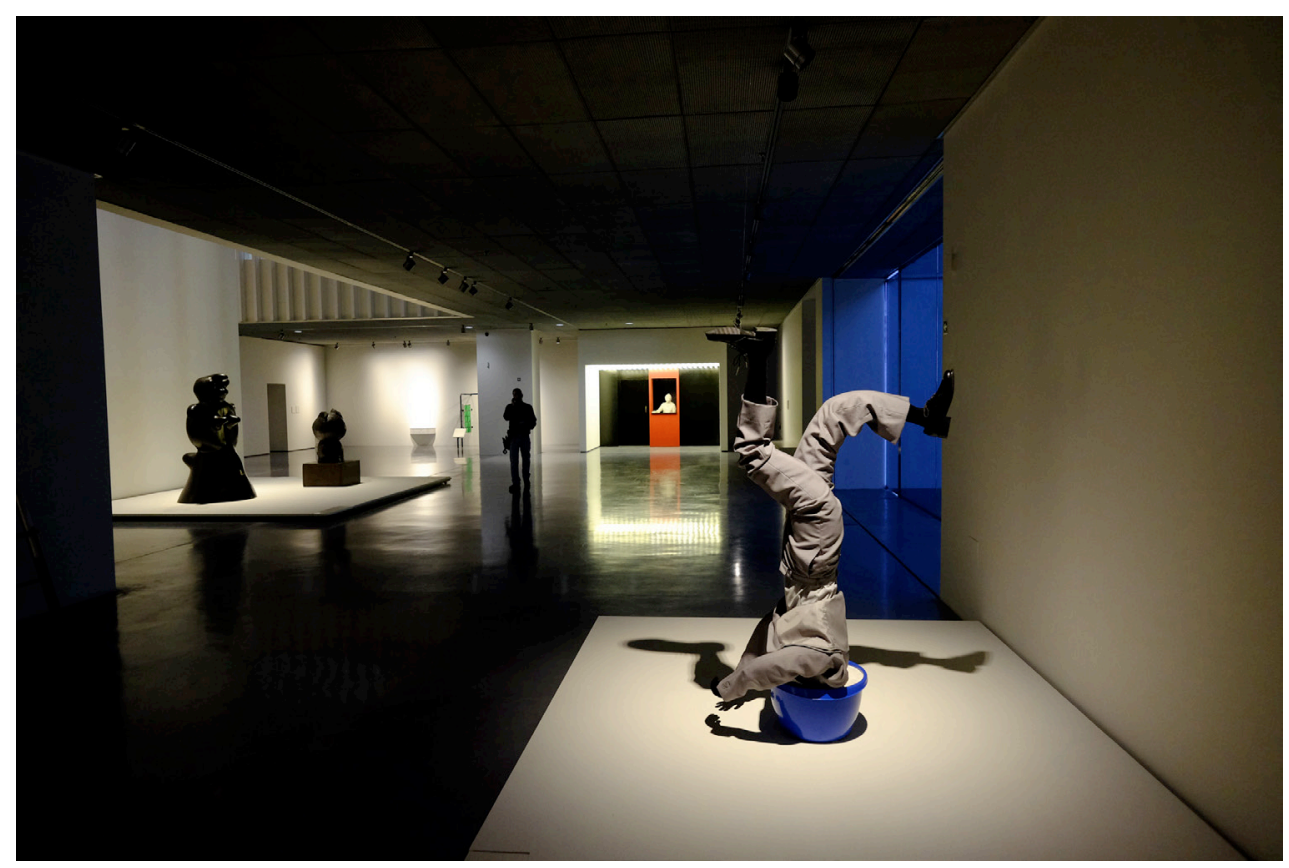

Vista del Centre Pompidou

No podemos dejar de citar en este punto una experiencia teórica germinal de esa fragmentación corporal: la desmembración del cuerpo en el «Diccionario crítico» que publicó entre 1929 y 1930 la disidente revista surrealista Documents, «capitaneada» por Georges Bataille, en la que se daban definiciones antidogmáticas de partes del cuerpo acompañadas por fotografías (boca, ojo o dedo gordo del pie).

Lo escatológico y lo abyecto se concentran en la sección «El cuerpo político», espacio también para discursos de género que alertan de la cosificación del cuerpo femenino. Es un espacio pequeño pero muy intenso, en el que vemos piezas sobresalientes, como un archivo emocionante de Annette Messager o acciones registradas en soporte videográfico de Ana de Mendieta y Carolee Schneemann. Aquí aparece el cuerpo tal como predicara Barbara Kruger, como "campo de batalla».

De una pertinencia extrema parece la primera muestra temporal, Corps simples. A ver cómo te mueves (compuesta por cinco vídeos y vídeo-instalaciones que durante el primer fin de semana se vieron acompañadas por performances), y el programa de proyecciones Vidéodanse (programa de vídeo en torno a la danza y su cercanía con el arte contemporáneo), pues el cuerpo es el motor, es el medio, es aquello que dibuja continuas intangibilidades. La danza -también el gesto- y las artes plásticas tuvieron un acercamiento fundamental hace décadas, pasada la mediación del XX. Sirvan como primigenios ejemplos algunas acciones realizadas al alimón por Merce Cunningham, John Cage y Robert Morris o, centrándonos en el escenario francés, las Antropometrías de Klein. Esto abre un escenario fundamental para el arte del siglo XX. Por un lado, el gesto como acción; pero también como tiempo, como duración y, en parte, como proceso. Y de ahí, por otro lado y parafraseando a Harold Rosenberg, al acontecimiento. Respecto a la intervención de Daniel Buren mediante paneles de color que ocupan el lucernario, el cubo vítreo que sobresale de la cota de tierra conformándose en hito del edificio, parece algo débil por no decir naï. Sin embargo, en el interior crece de manera prodigiosa, mostrándose, al proyectarse en algunas paredes, como objeto de contemplación y transformando espacios en lo que es un ejercicio de «pintura expandida». De hecho, la cambiante pero abundantísima luz natural que se filtra coloreada ilumina algunos espacios arrojándoles un «aura artística». Es el caso de la suerte de celosía que abraza el perímetro de la nave central y que nos permite, desde la planta alta, ver ese espacio según nos 


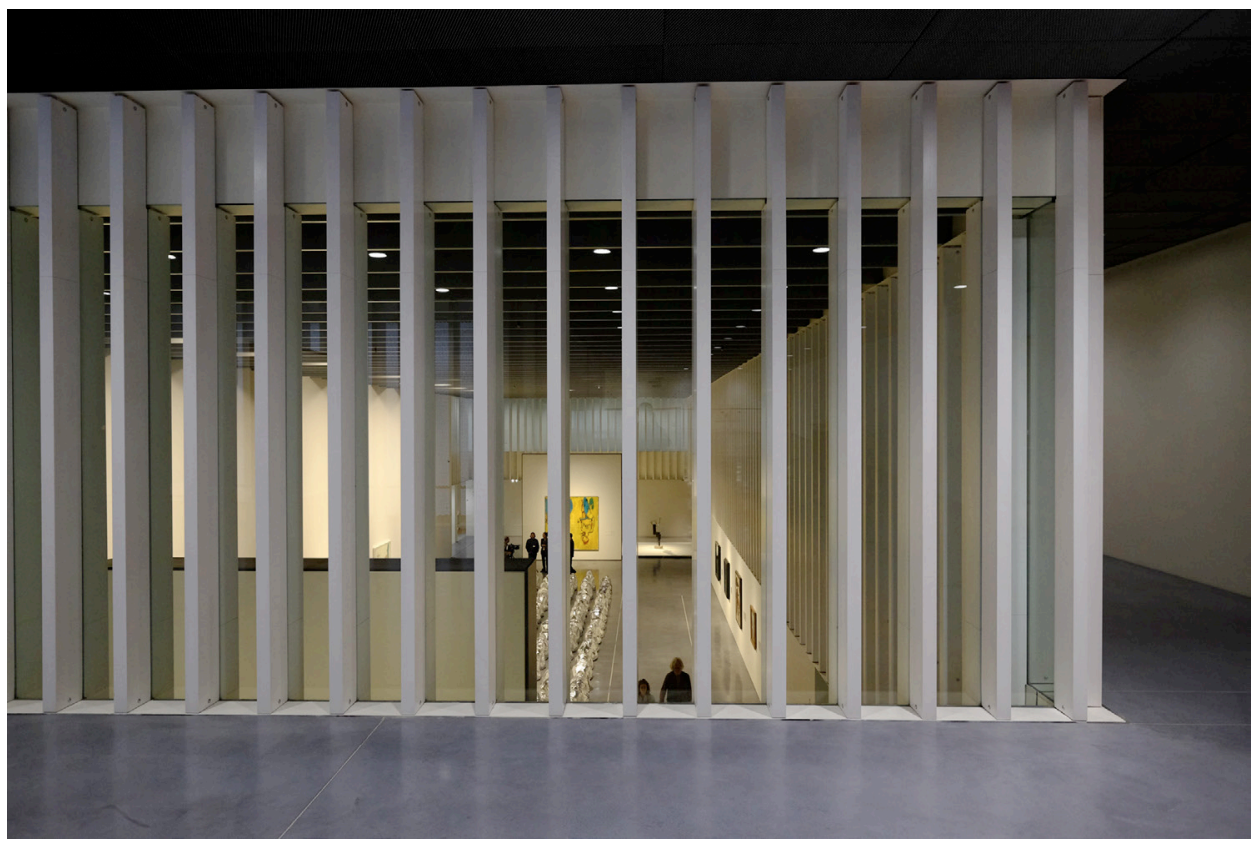

Vista del Centre Pompidou

disponemos a bajar al nivel inferior para iniciar la visita. La luz multicolor baña cada uno de los vástagos arquitectónicos (una especie de lamas o viguetas), haciendo que una solución arquitectónica que pasaría inadvertida cobre una inusitada importancia deviniendo desarrollo de estructuras primarias o minimalistas.

Los espacios infantiles con los que se dota el centro son aportaciones de una museografía que invita a interactuar. A lo largo del recorrido encontraremos puestos para experimentar con la identidad y una instalación dispersa de Tony Oursler, aceptando la idea de cuerpo despedazado antes mencionada. Ha de destacarse la exposición-taller Bajo la luna II, una obra-juego de Miquel Navarro, autor de Palera, la escultura monumental del Paseo Marítimo de Poniente. La propuesta es una de sus características instalaciones en las que recrea una ciudad en miniatura con distintos elementos abstractos. Ahora pasa a ser un espacio transitable para que los niños la descompongan y recompongan mientras experimentan con las escalas, la fenomenología de la percepción y el espacio público simbolizado. Como ven, asuntos gruesos del arte último desarrollados de manera lúdica. Además, vuelve a aparecer el cuerpo, que se descubre como ineludible mediador con el espacio.

\section{Arte ruso. De los iconos al siglo XX (exposición permanente) y La época de Diáguilev (temporal). Museo Estatal Ruso de San Petersburgo}

El desembarco del Museo Estatal Ruso de San Petersburgo en su sede de Málaga, en la bautizada como Colección del Museo Ruso, se hace mediante dos exposiciones, una con la paradójica categoría de permanente, que durará hasta noviembre de 2015, así como otra temporal que concluirá en julio, dando paso a una esperada segunda cita consagrada a la figura del represaliado artista Pável Filónov y que adquiere condición de verdadero acontecimiento. Como el propio título indica, Arte ruso. De los iconos al siglo XX, la muestra inaugural nace con la vocación de convertirse en una panorámica historia del arte ruso, con la intención de transmitirnos el relato historiográfico de la pintura rusa hasta prácticamente mediados del siglo XX.

La obra de llya Kabakov, el artista ruso más importante desde la segunda mitad del siglo XX, aunque nacido en Ucrania, se ha constituido desde los setenta como un espejo que proyecta un retrato del «alma rusa», de la esencia o del ser de su nación. Kabakov emplea el vacío, la nieve y la isla como metáforas. La isla aludiría a la incomunicación, 


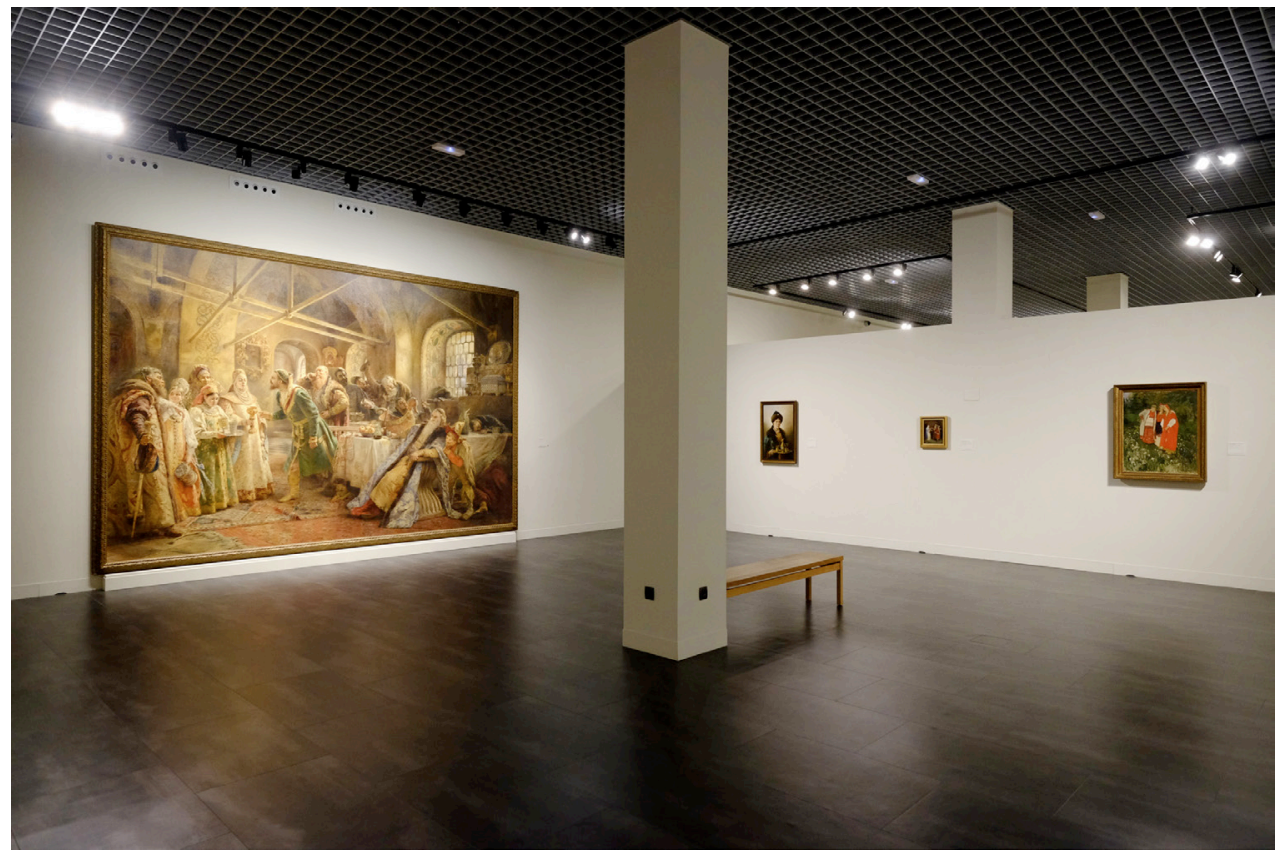

Vista del Museo Ruso

que el artista visibilizó como un rasgo tanto interno como entre el país y otras naciones. Sirva esta reflexión para señalar cómo los rectores del Museo Estatal de Arte Ruso de San Petersburgo pueden entender que su presencia en Málaga es un medio para difundir el relato historiográfico del arte ruso, para vencer el proverbial desconocimiento y para, como señalaba Vladimir Gusev, director del museo, romper con los lugares comunes en torno a la creación patria.

Parece lógico que la institución tenga un compromiso con el objeto que funda su existencia (la historia del arte local), de hecho sus copiosos fondos solo se nutren de ella, pero ese ansia por trasladárnosla puede operar, en algún momento, en contra de la selección de cien piezas que componen esta toma de contacto. Ese compromiso cabe entenderse como una "cuestión de Estado", un sentirse embajador y proyectar un país en el extranjero, que es, al fin y al cabo, lo que está haciendo el Museo Estatal de San Petersburgo. Como se imaginarán, en un centenar de piezas encontramos numerosas sobresalientes y otras que parecen incluirse en este discurso por su valor de testimonio, como suministradoras de información acerca de la nación de la que proceden, de su historia y de sus usos y costumbres. Ese «operar en contra» que señalábamos, no obstante, no se debe tanto a una cuestión de calidad de las piezas, al menos no exclusivamente, como a una cuestión de sobreabundancia de obras de algunas etapas y tendencias.

La exposición se inicia con una selección de iconos fechados entre los siglos XVI y XVII. La iluminación, íntima y escenográfica, y un tratamiento ambiental distinto al resto del recorrido, que consigue que nos aislemos del interior arquitectónico, potencian la intensidad y espiritualidad de estas obras devocionales. Debemos mantener el recuerdo de estas imágenes cuando accedamos a la sala de las vanguardias, pues servirá para ver cómo la «planitud» o énfasis por lo bidimensional, el esquematismo formal e icónico y cierto ingenuismo que presenciamos en ellas serían reeditados por algunos artistas de la vanguardia, tan influida en el caso ruso por el arte popular.

Pero antes de llegar a la vanguardia -sin duda la parte más brillante del recorrido- transitamos por el arte de los siglos XVII-XIX. Este deambular, a veces tedioso por lo reiterativo de la pintura de costumbres, nos suministra, además de algunas muy buenas piezas -sobresalen los decimonónicos Briulov, Ivánov o Repin, excelentes-, y alguna otra cuestionable, una serie de nociones acerca de la pintura rusa. Como «periferia», los artistas rusos irían aceptando las fórmulas es- 
tilísticas que surgen en los núcleos centrales del arte europeo, incorporando leves variaciones. Esa aceptación, como no puede ser de otra manera, no impide que se incorporen asuntos propios. Se aprecia, por tanto, una dinámica, conflictiva o no, dirigida a la síntesis de lo vernáculo y lo foráneo, a introducir la idiosincrasia en las formas exógenas. De este modo, se suceden las influencias, las citas y la reformulación de temas y metáforas características de distintas épocas (lo pastoril, el retrato aristocrático, las vedutes de las nuevas ciudades que se oponen a la continua presencia del campesinado como esencia, lo crepuscular y sublime románticos, el realismo o la mitología). Nada, en rigor, distinto a lo que sucede en otros muchos escenarios periféricos. De hecho, algunos cuadros de pintura de historia, por su escenificada afectación y por cierta vis orientalista, pueden traernos a la memoria ejemplos españoles de ese mismo género. Precisamente, las obras de temática española de Alexander Golovin ilustrarían cómo España y Rusia quedaron reunidas en el imaginario postromántico europeo como residencias de lo exótico y oriental -recuerden que Matisse visitaría Granada y Sevilla a principios del XX buscando esa identidad que perseguiría más tarde en el gigante euroasiático-.

El fenómeno del aggiornamento, de esa ansiada «puesta al día» respecto al ideal europeo, tiene un ejemplo palmario en el nacimiento de San Petersburgo (siglo XVIII) como ciudad-puente con Europa, viniendo a confrontarse con la continua visión y oda de la Rusia rural y del campesinado, una suerte de alegoría del «alma nacional». A este aspecto, a la naciente urbe de espíritu de occidental, que se contraponía a la más oriental y castiza Moscú, el relato reserva un buen número de piezas. Esa dimensión de Europa como ideal o aspiración para la cultura rusa se manifiesta en distintos y muy ilustrativos ejemplos. A saber, cómo Catalina II (siglo XVIII) coleccionó arte europeo, preferentemente francés, casi en paralelo al nacimiento de la Academia local, o cómo Morozov y Shchukin acumularon fabulosas colecciones de los primeros ismos, convirtiendo a Rusia en uno de los principales destinos en los que desembarcó masivamente el arte del cambio de siglo y de las primeras vanguardias.

Apenas sin solución de continuidad, con unos pocos destellos de los lenguajes de finales del XIX que irían progresivamente introduciendo la modernidad, nos encontramos con la vanguardia, momento en el que, invirtiéndose la dinámica, Rusia deja de ser periferia y se convierte en «centro»:

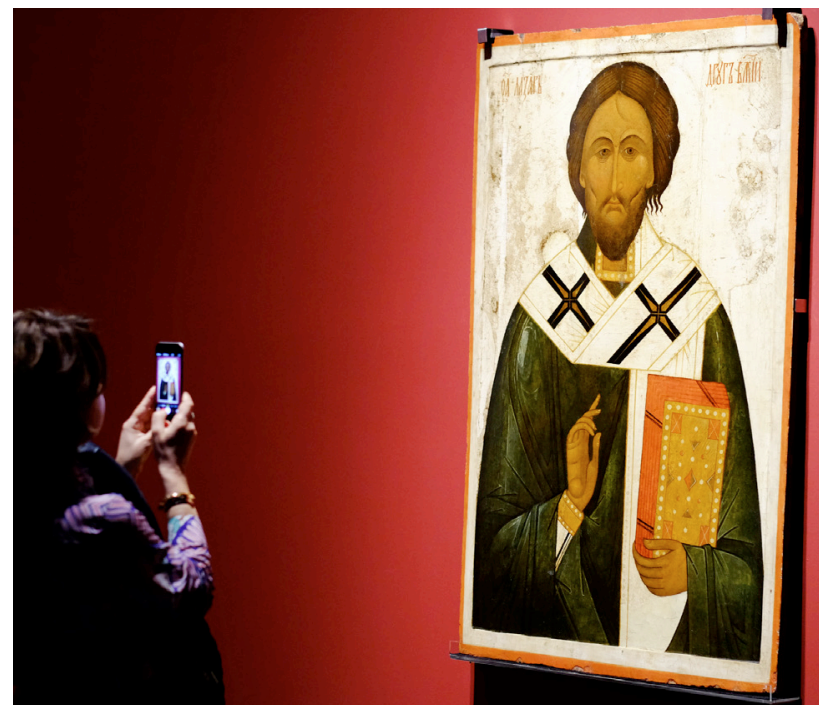

Vista del Museo Ruso

Europa pasa a mirar al foco ruso. Las obras en esta sección son, por lo general, estimables, con alguna rareza como el desnudo primitivista de Tatlin y con la presencia de diferentes estribaciones del expresionismo y la abstracción, como ocurre con Rózanova y Kandinski. Junto a estos, obras de Chagall, Rodchenko o Malevich conforman los puntales y los puntos cardinales de esa radical transformación. Más allá de los capitales nombres y piezas cubistas y constructivistas, este conjunto, demasiado ajustado en número, nos

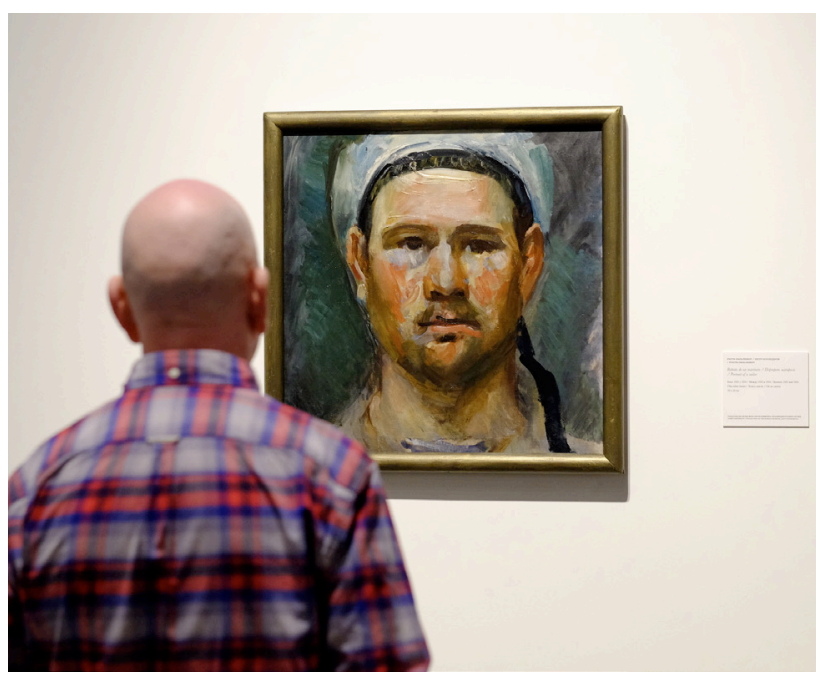

Vista del Museo Ruso 
acerca al intento de transformación y de consecución de un nuevo orden al que aspiró la vanguardia rusa, especialmente a través del productivismo y el diseño aparejado. Ahí adquieren importancia una serie de trabajos (decoraciones pictóricas sobre bandejas) del Instituto de Artes Decorativas de Leningrado.

Tras este (corto) periodo deslumbrante y de progreso y justicia social, la llegada de Stalin impone el realismo socialista. Algunos ejemplos son formidables en su factura y en el empleo del heroísmo. Los temas giran, en pos de un arte nacional dogmático y presuntamente edificante, en torno a la importancia del trabajo y la industria como símbolos patrios, tanto como sobre las más banales escenas de costumbres. Ha de valorarse que el discurso propuesto nos haga partícipes de esa imposición que arroja tanto obras excelentes, al margen del contenido, como otras intrascendentes y vulgares. Por desgracia, el relato historiográfico no atiende al arte de las últimas décadas del XX -fundamental resulta el conceptualismo moscovita de los ochenta y el Sots Art- ni a la fundamental cartelística de vanguardia. La inclusión de estos episodios hubiera dotado al discurso de mayor rigor y afán totalizador. Es deseable que para próximas propuestas se solventen estas lagunas y se economicen algunas etapas, permitiendo una mayor presencia de obras de los momentos fundamentales del arte ruso.

Queda igualmente inaugurada la primera temporal, La época de Diáguilev, exquisita muestra (69 obras) que viene a cubrir algunas lagunas de la permanente gracias a la presencia de obras a enmarcar en las «poéticas fin de siglo» y de otras que anuncian precozmente los «realismos de nuevo cuño» y el Art déco. Muchas de ellas, fechadas en las décadas del cambio de siglo, están guiadas por la perpetuación de la belleza y por el hedonismo, categorías y valores «derrocados» por las vanguardias; Picasso señalaba, en relación al cubismo, descrito por algunos autores como «laboratorio del arte», que no se le podía pedir belleza a una fórmula matemática. El conjunto, que elude la trascendental producción vanguardística en torno a los ballets rusos, es tremendamente sugerente y heterogéneo, concitándose magníficas piezas en clave simbolista, modernista y secesionista, así como ejemplos de recepción del divisionismo y del expresionismo alemán. No podemos dejar de destacar obras que se encuentran poderosamente influidas por algunas estribaciones del expresionismo alemán, como un estimable lienzo de Goncharova, un paisaje plomizo que posee un indudable débito con la obra de Franz Marc y Auguste Macke.

El conjunto consigue trasladar el círculo artístico cercano al promotor «danzístico», así como los rededores de la revista Mundo del Arte que creara. Por tanto, no aborda específicamente el fructífero periodo desde mediados de la segunda década del siglo XX en la que nacen algunos de sus espectáculos capitales, como tampoco, a excepción de un conjunto de bocetos para decorados, diseños de figurines y vestuario que podemos encontrar, supone una muestra dedicada a su compañía de ballet como generadora de una experiencia capital de integración de las artes a principios del siglo XX. No debemos olvidar que los ballets rusos de Diáguilev hicieron escala en Málaga en 1917, en el Teatro Cervantes, cercano a la casa natal de Picasso, colaborador fundamental que vino a dinamitar el concepto clásico de espectáculo de danza para transformarlo en algo cercano a la «obra de arte total».

Juan Francisco Rueda Crítico de arte de Sury ABC Cultural 